\title{
Magnetic Fields Modulate Blue-Light-Dependent Regulation of Neuronal Firing by Cryptochrome
}

\author{
Carlo N.G. Giachello, ${ }^{1} \oplus$ Nigel S. Scrutton, ${ }^{2,3}{ }^{\oplus A l e x}$ R. Jones, ${ }^{2,3,4}$ and $\odot$ Richard A. Baines ${ }^{1}$ \\ ${ }^{1}$ Faculty of Life Sciences, University of Manchester, Manchester M13 9PT, United Kingdom, ${ }^{2}$ Manchester Institute of Biotechnology, University of \\ Manchester, Manchester M1 7DN, United Kingdom, and ${ }^{3}$ Photon Science Institute and ${ }^{4}$ School of Chemistry, University of Manchester, Manchester M13 \\ 9PL, United Kingdom
}

Many animals are able to sense the Earth's geomagnetic field to enable behaviors such as migration. It is proposed that the magnitude and direction of the geomagnetic field modulates the activity of cryptochrome (CRY) by influencing photochemical radical pair intermediates within the protein. However, this proposal will remain theoretical until a CRY-dependent effect on a receptor neuron is shown to be modified by an external magnetic field (MF). It is established that blue-light (BL) photoactivation of CRY is sufficient to depolarize and activate Drosophila neurons. Here, we show that this CRY-dependent effect is significantly potentiated in the presence of an applied MF $(100 \mathrm{mT})$. We use electrophysiological recordings from larval identified motoneurons, in which CRY is ectopically expressed, to show that BL-dependent depolarization of membrane potential and increased input resistance are markedly potentiated by an MF. Analysis of membrane excitability shows that these effects of MF exposure evoke increased action potential firing. Almost nothing is known about the mechanism by which a magnetically induced change in CRY activity might produce a behavioral response. We further report that specific structural changes to the protein alter the impact of the MF in ways that are strikingly similar to those from recent behavioral studies into the magnetic sense of Drosophila. These observations provide the first direct experimental evidence to support the hypothesis that MF modulation of CRY activity is capable of influencing neuron activity to allow animal magnetoreception.

Key words: action potential; cryptochrome; depolarization; Drosophila; magnetic field; radical pair

\section{Significance Statement}

The biophysical mechanism of animal magnetoreception is still unclear. The photoreceptor protein cryptochrome has risen to prominence as a candidate magnetoreceptor molecule based on multiple reports derived from behavioral studies. However, the role of cryptochrome as a magnetoreceptor remains controversial primarily because of a lack of direct experimental evidence linking magnetic field (MF) exposure to a change in neuronal activity. Here, we show that exposure to an MF (100 mT) is sufficient to potentiate the ability of light-activated cryptochrome to increase neuronal action potential firing. Our results provide critical missing evidence to show that the activity of cryptochrome is sensitive to an external MF that is capable of modifying animal behavior.

\section{Introduction}

Many animals can sense the geomagnetic field to enable behaviors including migration. Experimental evidence, mainly derived

Received July 5, 2016; revised Aug. 2, 2016; accepted Aug. 18, 2016.

Author contributions: C.N.G.G., A.R.J., and R.A.B. designed research; C.N.G.G. performed research; C.N.G.G. and R.A.B. analyzed data; C.N.G.G., N.S.S., A.R.J., and R.A.B. wrote the paper.

Work on this project benefited from the Manchester Fly Facility, established by the University of Manchester and the Wellcome Trust (Grant 087742). R.A.B. acknowledges support from the Medical Research Council, UK (Grant MR/J009180/1). A.R.J. and N.S.S. thank the University of Manchester, the Electromagnetic Fields Biological Research Trust, and the Colt Foundation for funding. We thank Dr. RalfStanewsky (University College London), Giorgio Fedele (University of Leicester), and Charalambos Kyriacou (University of Leicester) for providing the cry mutant flies.

The authors declare no competing financial interests.

This article is freely available online through the J Neurosci Author Open Choice option.

Correspondence should be addressed to either of the following: Alex R. Jones, Photon Science Institute, University of Manchester, John Garside Building-G.028, Oxford Road, M13 9PL Manchester, United Kingdom, from behavioral assays, supports the existence of magnetoreceptors, not only in migrating animals (e.g., species of birds, marine turtles and lobsters; Wiltschko and Wiltschko, 2005), but also in simpler organisms that do not migrate but are easier to investigate, including the fruit fly Drosophila melanogaster (Phillips and Sayeed, 1993; Gegear et al., 2008; Yoshii et al., 2009; Gegear et al., 2010; Painter et al., 2013; Bae et al., 2016). The magnetic sense of Drosophila is dependent on the wavelength of light to which it is

E-mail: alex.jones-2@manchester.ac.uk; or Richard A. Baines, Faculty of Life Sciences, University of Manchester, AV Hill-1.016, 0xford Road, M13 9PT Manchester, United Kingdom, E-mail: richard.baines@manchester.ac.uk. D0I:10.1523/JNEUROSCI.2140-16.2016

This is an Open Access article distributed under the terms of the Creative Commons Attribution License Creative Commons Attribution 4.0 International, which permits unrestricted use, distribution and reproduction in any medium provided that the original work is properly attributed. 
exposed and on the presence of a circadian photoreceptor protein, cryptochrome (CRY) (Gegear et al., 2008). CRYs are widespread throughout nature and, in animals (including migratory birds), have well described circadian roles as either photoreceptors or light-independent transcriptional regulators (Ceriani et al., 1999; Griffin et al., 1999). CRYs with known photoreceptor function contain a noncovalently bound, blue-light (BL) chromophore called flavin adenine dinucleotide (FAD) (Zoltowski et al., 2011; Levy et al., 2013) and are putative magnetoreceptors (Dodson et al., 2013). CRY-dependent magnetoreception is currently proposed to be a result of light-initiated electron transfer chemistry in the protein, which might be magnetically sensitive by virtue of the radical pair mechanism (RPM) (Rodgers and Hore, 2009; Dodson et al., 2013; Hore and Mouritsen, 2016; Jones, 2016). Indeed, magnetically sensitive radical pair reaction dynamics have been observed in the photoresponse of isolated CRYs from Arabidopsis (Maeda et al., 2012; Kattnig et al., 2016) and extensive theoretical work indicates that CRY photochemistry has a number of properties ideal for a biological magnetic sensor (Dodson et al., 2013). However, there is as yet no direct in vivo evidence that CRY is a magnetoreceptor and the possible identity of the magnetically sensitive radical pair in CRY is currently a matter of considerable debate (Hogben et al., 2009; Solov'yov and Schulten, 2009; Nießner et al., 2014; Wiltschko et al., 2016).

To produce a magnetically induced behavioral response, it is expected that CRY activity should be altered by the presence of a magnetic field (MF) that, in turn, will be transduced to a change in neuronal activity (Mouritsen et al., 2004; Johnsen and Lohmann, 2005; Lohmann, 2010). CRY from the migratory garden warbler is found in retinal cells that show high levels of neuronal activity at night (Mouritsen et al., 2004) and overexpression of CRY in Drosophila clock neurons enhances the effects of MF exposure on the circadian period (Yoshii et al., 2009; Fedele et al., 2014b). To date, however, there has been no clear direct demonstration that CRY can facilitate a magnetically induced response in neuronal activity. We showed previously that MF exposure coupled with CRY photoactivation during embryogenesis is sufficient to produce heightened seizure susceptibility in resultant Drosophila third instar (L3) larvae (Marley et al., 2014). We hypothesized that this effect is due to alteration in neuronal activity levels during an embryonic sensitive period (Giachello and Baines, 2015) induced by photoactivated CRY and potentiated by an MF. Here, we provide direct evidence of CRY- and lightdependent MF modulation of action potential firing in individual identified neurons. Current-clamp recordings from the larval “anterior Corner Cell" (aCC) and "Raw Prawn 2" (RP2) motoneurons, ectopically expressing CRY, reveal a BL-dependent depolarization in membrane potential, an increase in input resistance, and a heightened firing rate. These effects are significantly potentiated by concomitant MF exposure (100 mT), validating our hypothesis that magnetically induced changes in CRY activity can produce an organism response by influencing neuronal activity.

\section{Materials and Methods}

Fly stocks. Flies were maintained on standard corn meal medium at $25^{\circ} \mathrm{C}$. The following fly stocks were kindly provided by the respective individuals: ${ }^{-}{ }^{-}$; UAS-cry ${ }^{24.5} / \mathrm{CyO}$, act::GFP; + (Ralf Stanewsky; Emery et al., 2000); $\mathrm{w}^{-}$, UAS-cry ${ }^{\Delta 14.6}$; +; + and $\mathrm{y}^{-}, \mathrm{w}^{-}$; UAS-cry ${ }^{\text {W342F }}$ (Giorgio Fedele; Fedele et al., 2014b). These stains were crossed with the strong pan-neuronal driver line $\mathrm{ElaV}^{\mathrm{C} 155}$-GAL4; +; + (obtained from the Bloomington Drosophila Stock Center).
Electrophysiological recordings. Recordings were performed in wallclimbing L3 larvae of either sex at room temperature $\left(22-24^{\circ} \mathrm{C}\right)$ as described previously (Baines and Bate, 1998). aCC/RP2 motoneurons were recorded in whole-cell current-clamp mode and held at $-60 \mathrm{mV}$. Thickwalled borosilicate glass electrodes (GC100F-10; Harvard Apparatus) were fire polished to resistances of $10-15 \mathrm{M} \Omega$. Recordings were made using a Multiclamp 700B amplifier controlled by pCLAMP (version 10.4) via a Digidata $1440 \mathrm{~A}$ analog-to-digital converter (Molecular Devices). Traces were sampled at $20 \mathrm{kHz}$ and filtered online at $10 \mathrm{kHz}$. The external saline solution contained the following (in mM): $135 \mathrm{NaCl}, 5$ $\mathrm{KCl}, 4 \mathrm{MgCl}_{2} \cdot 6 \mathrm{H}_{2} \mathrm{O}, 2 \mathrm{CaCl}_{2} \cdot 2 \mathrm{H}_{2} \mathrm{O}, 5 \mathrm{TES}$, and 36 sucrose, $\mathrm{pH}$ 7.15. All recordings were performed in the presence of $1 \mathrm{~mm}$ mecamylamine to block endogenous cholinergic synaptic currents (i.e., synaptically isolating the aCC/RP2 neurons from all known excitatory inputs). The internal patch solution contained the following (in mM): $140 \mathrm{~K}^{+}$-Dgluconate, $2 \mathrm{MgCl}_{2} \cdot 6 \mathrm{H}_{2} \mathrm{O}, 2 \mathrm{EGTA}, 5 \mathrm{KCl}$, and $20 \mathrm{HEPES}$, pH 7.4. $\mathrm{KCl}$ and $\mathrm{CaCl}_{2}$ were from Fisher Scientific; sucrose was from $\mathrm{BDH}$; all remaining chemicals were from Sigma-Aldrich.

Photoactivation of CRY was achieved by using a $100 \mathrm{~W}$ short arc mercury lamp (USH-102D; Ushio) connected to an Olympus BX51WI microscope and filtered at $470 \pm 20 \mathrm{~nm}(\mathrm{HQ} 470 / 40 \times)$. Alternatively, on orange LED (orange light, OL; $590 \pm 18 \mathrm{~nm}$; Cairn Research) was used as the excitation source. Light intensity, measured with a LI-250A light meter (LI-COR), was $22 \pm 5 \mathrm{~mW} \mathrm{~cm}{ }^{-2}$ for BL $\left(\sim 5.1 \times 10^{16}\right.$ quanta s $^{-1}$ $\left.\mathrm{cm}^{-2}\right)$ and $4 \pm 0.2 \mathrm{~mW} \mathrm{~cm}^{-2}$ for OL $\left(\sim 1.8 \times 10^{16}\right.$ quanta s$\left.{ }^{-1} \mathrm{~cm}^{-2}\right)$. These values are similar to those used previously to stimulate CRYexpressing neurons, where $2-3 \mathrm{~mW} \mathrm{~cm}^{-2}$ was demonstrated as sufficient to ensure adequate Drosophila CRY photostimulation (Fogle et al., 2011). Each cell was recorded both in darkness and under light exposure. These experiments were repeated in the presence of an MF from a pair of $\mathrm{NeFeB}$ permanent magnets placed at a distance of $1.5 \mathrm{~cm}$ from the sample, where the MF was measured to be $100 \pm 6 \mathrm{mT}$. For electrophysiological investigations, a larval CNS was positioned at the center between the magnets with the same anterior-posterior orientation, which was aligned parallel to the magnet separation axis. Membrane potential changes in response to CRY photoactivation were calculated as $\Delta V \mathrm{~m}=$ $\left(V_{\mathrm{m}}+\mathrm{BL}\right)-\left(V_{\mathrm{m}}-\mathrm{BL}\right)$. Resting membrane potential (RMP) was assessed for each cell in zero current-clamp mode before any stimulation.

Input resistance was measured from the steady-state responses to a series of hyperpolarizing and subthreshold depolarizing current steps (4 $\mathrm{pA} / 1 \mathrm{~s}$ long) as the slope of a linear fit to the resulting voltage-current relationship (from $-12 \mathrm{pA}$ to $+8 \mathrm{pA}$ ). The same stimulation protocol was repeated twice, before and after constant BL exposure. To confirm the involvement of potassium currents in this process (Fogle et al., 2011), a set of recordings was repeated in the presence of potassium channel inhibitors (50 mm tetraethylammonium, $10 \mathrm{~mm} 4$-aminopyridine, and 5 mM cesium chloride).

Membrane excitability was determined as the number of action potentials fired by a series of rectangular depolarizing current pulses ( $4 \mathrm{pA}$ steps, from 0 to $60 \mathrm{pA} / 1 \mathrm{~s}$ long). The mean number of evoked action potentials elicited by incremental current injections was counted for each event.

Statistical analysis. Data are expressed as means \pm SEM. Statistical analysis was performed using GraphPad Prism version 6. Sample size $(n)$ is reported in each bar. Statistical significance was determined between pairwise comparisons only (e.g., \pm MF or $\pm B L$ ) using Student's paired or unpaired $t$ tests, as appropriate. Results from different genotypes are shown together in figures to conserve space. To assess membrane excitability, the input-output relationship was evaluated by linear fitting using GraphPad Prism version 6 and analyzed for significance using an ANCOVA model. Significance levels were set at $p<0.05$.

\section{Results}

To determine whether exposure to an MF can influence firing activity of Drosophila neurons, we mounted a pair of NeFeB permanent magnets around the electrophysiological preparation (see Materials and Methods). We used the same MF intensity, 100 $\mathrm{mT}$, as used previously for our experiments performed on embryos and seizure behavior (Marley et al., 2014). An MF of this 

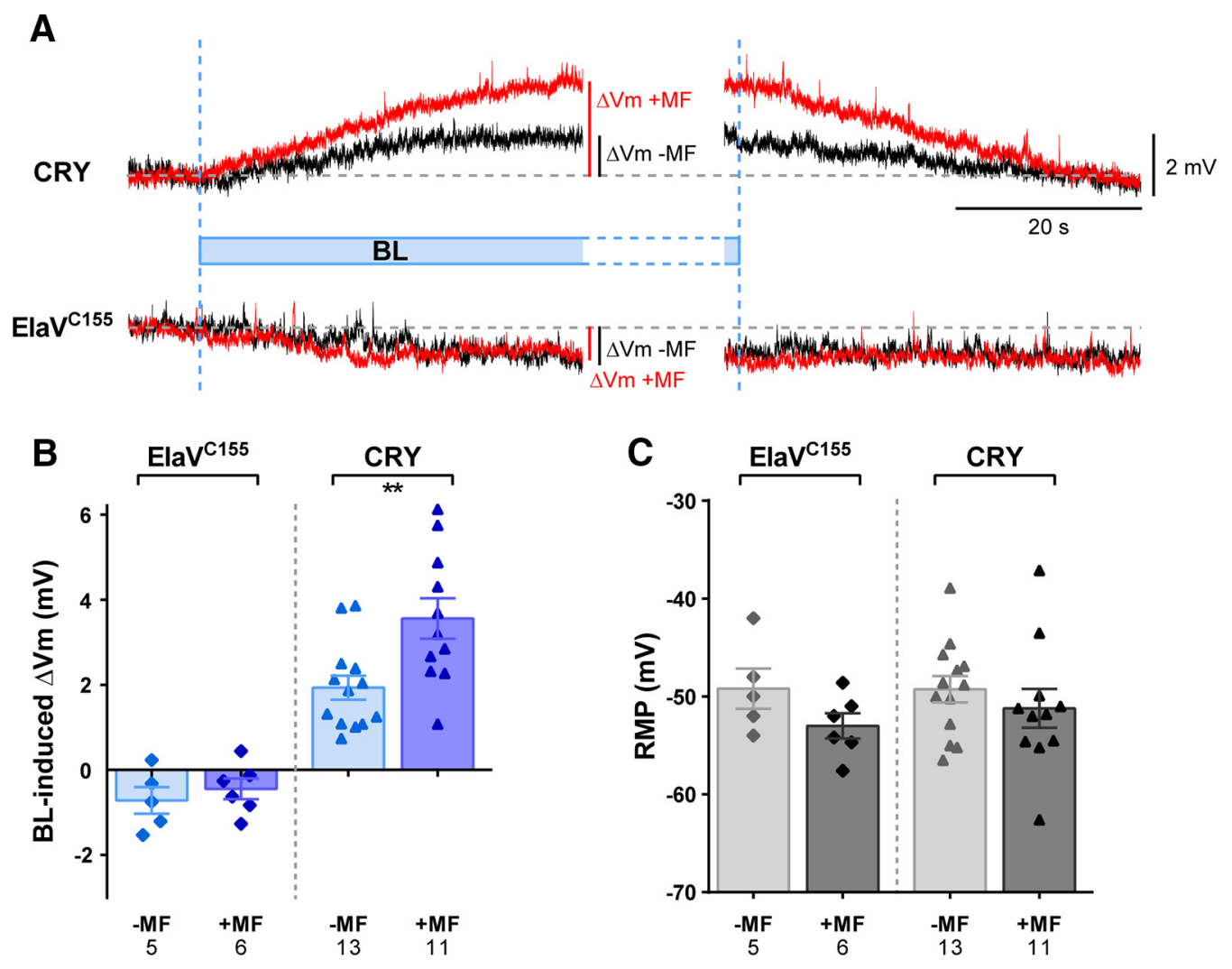

Figure 1. MF exposure potentiates the BL-evoked depolarization of the membrane potential. $A$, Representative electrophysiological recordings from L3 aCC/RP2 ectopically expressing wild-type cry. Reversible changes in $V_{m}$ were observed after BL exposure in presence or absence of a $100 \mathrm{mT}$ MF. No detectable increase in $V_{\mathrm{m}}$ was exhibited by the control group (Gal4 ElaV ${ }^{\mathrm{C} 155}$ ). B, Quantitative analysis of MF effect on the $B L$-induced $V_{m}$ changes to control cells and cells expressing CRY. $C$, No difference in RMP, which was measured before light stimulation, was observed in any experimental group. All values shown are means \pm SEM and $n$ is shown in each bar. ${ }^{* *} p<0.01$.

magnitude saturates the Zeeman effect of typical organic radical pairs (Woodward, 2002), but is insufficient to produce a thermodynamic effect (i.e., heating) in a biological system (Jones, 2016). An MF effect because of the RPM is therefore predicted and this experimental approach mitigates many of the problems and confounding variables associated with weak MFs generated by electromagnets under laboratory conditions (for a full discussion, see Marley et al., 2014). Recordings were conducted on aCC/RP2 dorsal motoneurons in L3 CNS, which does not express the endogenous cry gene (Emery et al., 2000). However, these motoneurons are easily accessible to electrophysiological investigation and their properties have been characterized extensively (Baines et al., 1999; Baines et al., 2001; Baines, 2004). These features make them particularly suitable to study alterations induced by CRY photoactivation, the expression of which can be easily achieved using the GAL4/UAS system ( $\mathrm{ElaV}^{\mathrm{C} 155}$-GAL4>UAS-cry).

\section{MFs potentiate the CRY-induced increase in membrane potential}

CRY mediates a light-evoked increase in membrane potential in large lateral ventral neurons (ILNv's) in the adult Drosophila brain and also when ectopically expressed in nonclock neurons (Fogle et al., 2011). Similarly, we found that ectopic expression of CRY in larval aCC/RP2 motoneurons is similarly sufficient to produce an appreciable and reversible depolarization in membrane potential on exposure to BL $(470 \pm 40 \mathrm{~nm} ; \Delta 1.93 \pm 0.28$ $\mathrm{mV}, n=13$; Fig. $1 A, B)$. The effect of BL is CRY specific and no effect was observed in wild-type animals (parental line ElaV ${ }^{\mathrm{C} 155}$ ), which instead showed a slight, but steady, hyperpolarization of the membrane potential $(\Delta-0.72 \pm 0.31 \mathrm{mV}, n=5$; Fig. $1 A, B)$, which occurs independently from light stimulation (we frequently observed a slow hyperpolarization in wild-type recordings). Our recording saline contained the cholinergic blocker mecamylamine, which removes all excitatory synaptic drive to motoneurons (Baines et al., 1999). Therefore, we discount the possibility that CRY-dependent effects observed in aCC/RP2 are due to change in activity of presynaptic neurons.

Significantly, repeating the BL illumination in the presence of a static MF potentiated the effect of CRY to produce almost double the level of depolarization $(\Delta 3.56 \pm 0.47 \mathrm{mV}, n=11$; Fig. $1 A, B)$. An unpaired $t$ test revealed a significant difference between the $-\mathrm{MF}$ and $+\mathrm{MF}$ groups $(p=0.0056$; Fig. $1 B)$. No MF-related effect was observed in the control group not expressing CRY $\left(\mathrm{ElaV}^{\mathrm{C} 155}\right.$ : $-\mathrm{MF}=-0.72 \pm 0.31 \mathrm{mV}, n=5$, $\mathrm{vs}+\mathrm{MF}=-0.45 \pm 0.24 \mathrm{mV}, n=6)$. The mean cell capacitance of motoneurons (a measure of cell size) in $-\mathrm{MF}$ and $+\mathrm{MF}$ was not statistically different $(12.73 \pm 0.78$ vs $12.90 \pm 0.80 \mathrm{pF},-\mathrm{MF}$ vs $+\mathrm{MF}$, respectively).

Oxidized CRY, which action spectra suggest is the resting state in vivo (Ahmad et al., 2002), does not significantly absorb wavelengths of light longer than $\sim 530 \mathrm{~nm}$ (VanVickle-Chavez and Van Gelder, 2007). Therefore, as a further control, we tested the effect of MF exposure on membrane potential after exposure to OL $(590 \pm 18 \mathrm{~nm})$. We observed no detectable light or light + MF-induced changes $(+\mathrm{OL},-\mathrm{MF}=\Delta-0.53 \pm 0.15 \mathrm{mV}$, $n=10$, vs $+\mathrm{OL},+\mathrm{MF}=\Delta-0.55 \pm 0.33 \mathrm{mV}, n=10, p=0.96)$, obtaining values similar to those measured in the control group $\left(\mathrm{ElaV}^{\mathrm{C} 155}\right)$. We showed previously that exposure to OL does not 
A
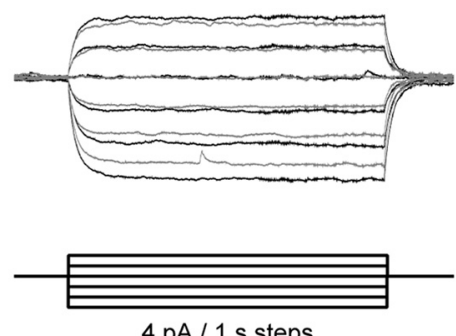

$4 \mathrm{pA} / 1 \mathrm{~s}$ steps

\section{B}

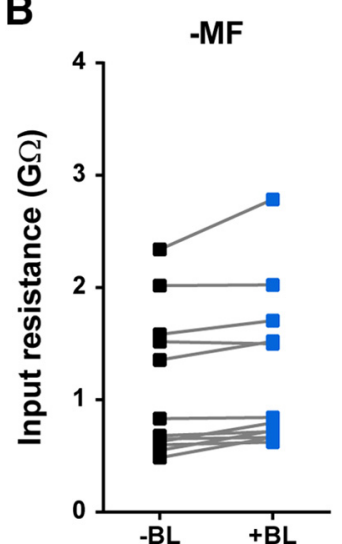

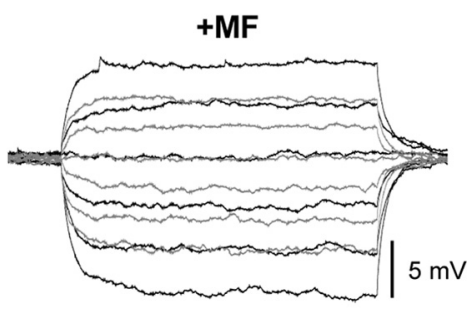

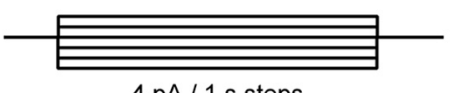

$4 \mathrm{pA} / 1 \mathrm{~s}$ steps

C

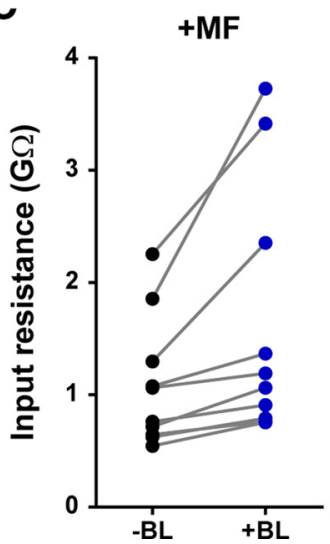

Figure 2. MF exposure potentiates the BL-evoked increase in input resistance. $A$, Series of current steps $(4 \mathrm{pA} / 1 \mathrm{~s})$ ranging from -12 to $+8 \mathrm{pA}$ applied before (gray traces) and during (black traces) BL exposure in the absence ( $-\mathrm{MF}$ ) and presence (+MF) of a $100 \mathrm{mT}$ MF. $B, C$, Effect of BL exposure on input resistance in the absence or presence of the MF.

affect the electroshock-induced seizure phenotype in larvae derived from photo-stimulated embryos (Marley et al., 2014). The inability of an MF to influence membrane potential under OL also negates possible interference via electromagnetic induction in our recordings (in this instance, the MF field inducing a current in the recording electrode). As a further control, all of the cells used in these experiments were pretested in current-clamp (with no current injection) to measure the basal RMP before proceeding with any light stimulation. No detectable changes in RMP were observed between the $-\mathrm{MF}$ and $+\mathrm{MF}$ conditions in the absence of light exposure in the different genotypes analyzed (Fig. 1C). These data imply that MF exposure has no significant effect on the membrane potential when CRY is not present, not photoactivated, or exposed to OL.

\section{MF exposure potentiates CRY-induced increase in input resistance}

The input resistance of a neuron reflects the extent to which membrane channels are open. Therefore, we investigated how this intrinsic membrane property is influenced by both CRY photoactivation and the co-presence of an MF. CRY-expressing aCC/RP2 motoneurons were tested before and during BL exposure by applying a series of hyperpolarizing and subthreshold depolarizing current steps ( $4 \mathrm{pA} / 1 \mathrm{~s}$ long; Fig. $2 A$ ). In the absence of an MF, CRY photoactivation induces a significant increase in input resistance from $1.10 \pm 0.18$ to $1.20 \pm 0.20 \mathrm{G} \Omega(p=0.03$, paired $t$ test, $n=12$; Fig. 2B). Similarly, an increase from $1.08 \pm$ 0.18 to $1.52 \pm 0.35 \mathrm{G} \Omega(p=0.04$, paired $t$ test, $n=10$; Fig. $2 C)$ was measured in the presence of an MF. Comparing the two datasets, we found that the BL-induced change in input resistance is significantly potentiated by the co-presence of an MF
$\left(\Delta \operatorname{Res}_{\text {input }}=0.09 \pm 0.59\right.$ vs $0.59 \pm 0.18$ $\mathrm{G} \Omega,-\mathrm{MF}$ vs $+\mathrm{MF}, p=0.0097$, unpaired $t$ test).

Previous work shows that light-evoked and CRY-mediated membrane depolarization in ILNv's is dependent on inactivation (i.e., closure) of Hyperkinetic (HK), a $\beta$-subunit of voltage-gated potassium channels (Shaker and Ether-a-go-go) that contains a conserved redox sensor. The presence of potassium channel inhibitors (tetraethylammonium, 4-aminopyridine, and cesium chloride) is sufficient to block this effect of CRY in ILNv's (Fogle et al., 2015). To determine whether CRY acts via a similar mechanism in aCC/RP2, we repeated our experiments in the presence of these blockers. BL activation of CRY produced no change to membrane potential in the presence of blockers $(\Delta-0.11 \pm 0.37$ $\mathrm{mV}, n=6$ ), supporting the hypothesis that CRY-mediated potassium channel inactivation underlies increased membrane depolarization in all neuron types in which it is expressed.

\section{MFs potentiate the CRY-induced} increase in membrane excitability CRY increases the spontaneous action potential firing rate in response to $\mathrm{BL}$ in Drosophila circadian neurons (Sheeba et al., 2008; Fogle et al., 2011). An increased hyperactivity of neuronal circuitry is also consistent with an increased seizure phenotype in larvae derived from MF coupled to BL exposure (Marley et al., 2014; Giachello and Baines, 2015). Excitatory synaptic inputs to Drosophila motoneurons show considerable variability, making determination of effect to spontaneous firing more challenging. To overcome this, we injected above-threshold depolarizing current pulses (4 pA steps, 0-60 pA/1 s long; Fig. 3) in aCC/RP2 and counted the number of action potentials fired (i.e., a standard input-output determination). This was determined in the presence of mecamylamine to block the endogenous synaptic excitation of these neurons. An ANCOVA revealed significant differences in the regression coefficients (slopes) of the input-output curves measured during BL exposure in the absence and presence of an $\mathrm{MF}(+\mathrm{BL},-\mathrm{MF}$ vs $+\mathrm{BL},+\mathrm{MF} ; F_{(1,274)}=26.51, p<0.0001$; Fig. $\left.3 A\right)$. Conversely, no detectable effect of MF was observed comparing the $-\mathrm{MF}$ and $+\mathrm{MF}$ groups in darkness $(-\mathrm{BL},-\mathrm{MF}$ vs $-\mathrm{BL},+\mathrm{MF} ; p>0.99$, data not shown). These results suggest that exposure to a moderate MF is sufficient to potentiate the effect of CRY photoactivation in increasing neuron action potential firing rate.

\section{Trp triad is not required for CRY-dependent sensitivity to an MF}

The precise mechanism of magnetoreception by CRY remains unknown. A prevailing view implicates a triad of tryptophan residues to facilitate a RPM that is sensitive to external MFs. To determine whether a Trp triad is required for the potentiation of CRY activity in motoneurons, we expressed the $\mathrm{CRY}{ }^{\mathrm{W} 342 \mathrm{~F}}$ variant, which replaces a conserved tryptophan (W342) with a redox inactive phenylalanine, thus disrupting the Trp triad responsible for donating electrons to the FAD cascade during light activation (Kao et al., 2008; Immeln et 
A

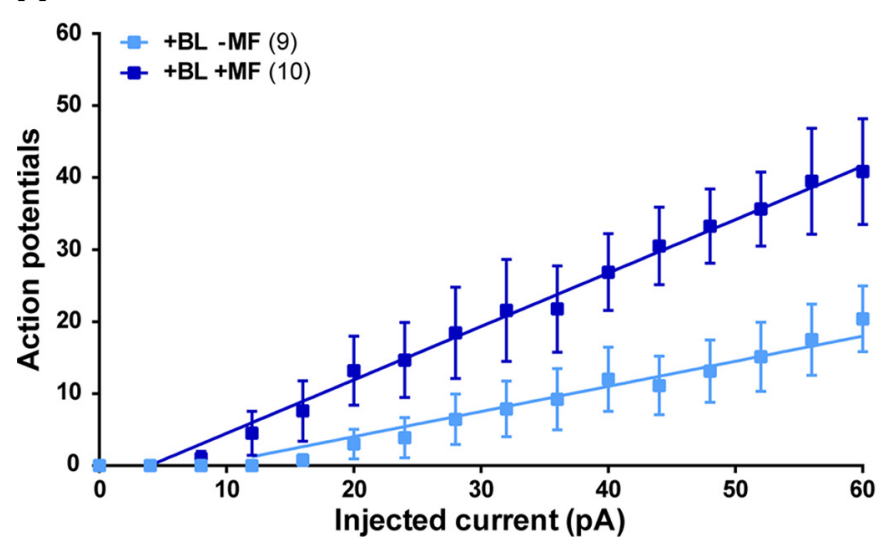

B
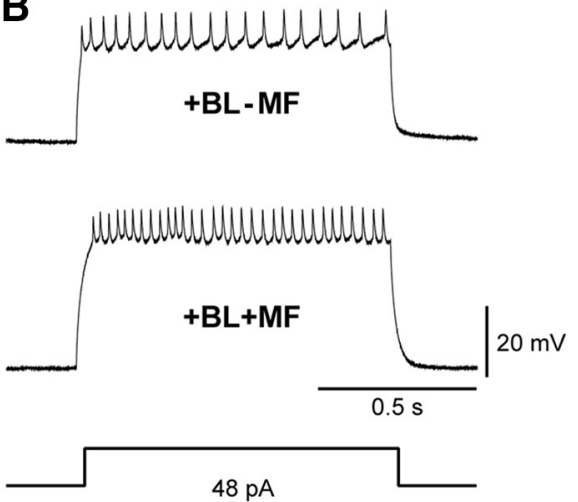

Figure 3. MF exposure enhances action potential firing. $A$, Input- output relationship of $L 3$ aCC/RP2 motoneurons determined by successively greater depolarizing current injections ( $4 \mathrm{pA}$ steps, $0-60 \mathrm{pA} / 1 \mathrm{~s}$ ) in the presence (dark blue) or absence (pale blue) of an MF (100 mT). All values shown are means \pm SEM. $B$, Representative traces showing the firing of action potentials evoked by injection of a $48 \mathrm{pA}$ current pulse.

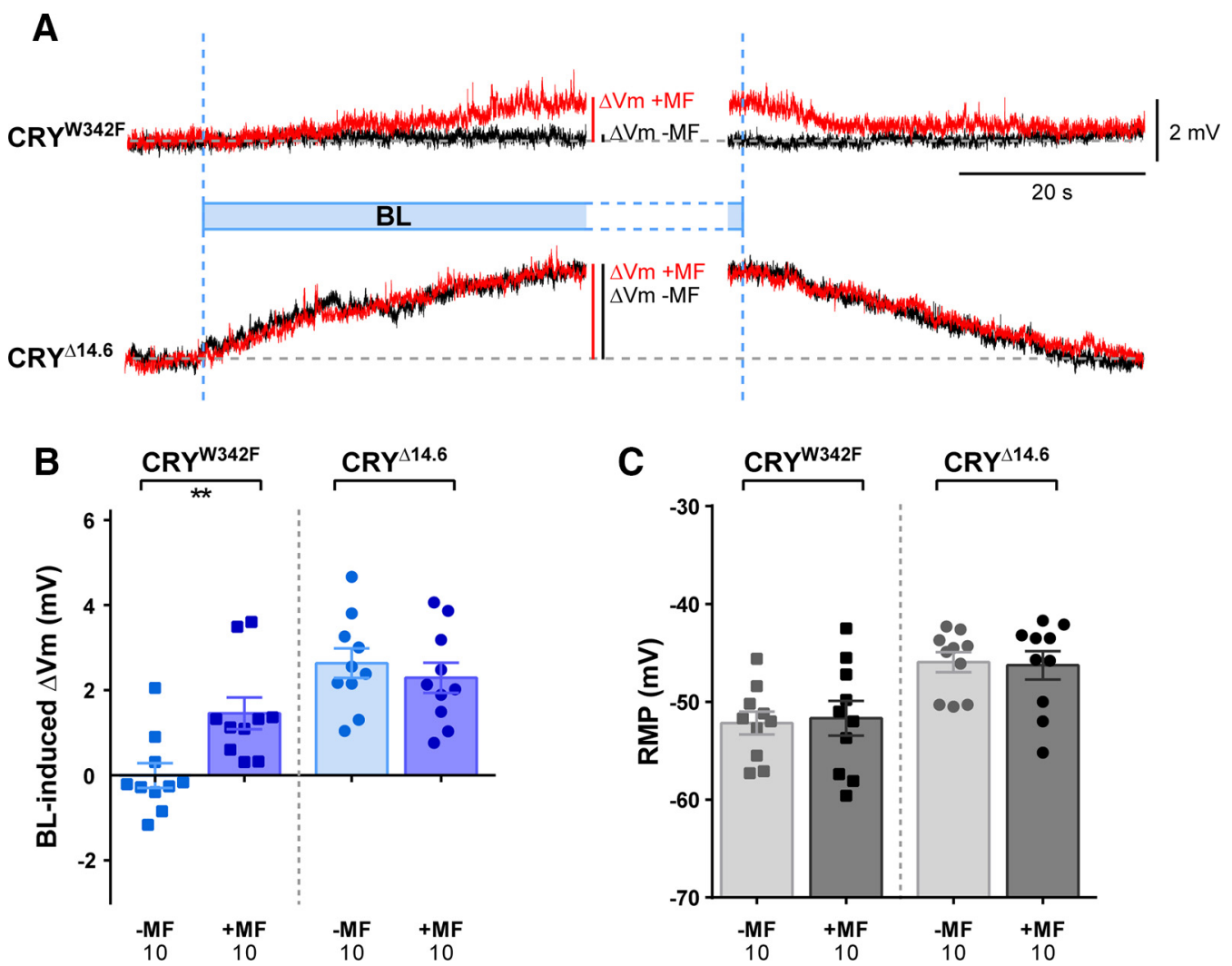

Figure 4. CRY variants show divergent sensitivity to MF exposure. $\boldsymbol{A}$, Representative electrophysiological recordings from L3 aCC/RP2-expressing CRY variants: CRY W342F and a C-terminal truncation $\left(C R Y^{\Delta 14.6}\right)$. Mutagenesis of W342 within the triad responsible for the RPM reveals that this residue is not essential for the MF response. Conversely, deletion of the CRY C-terminus dramatically affects the MF-dependent potentiation without compromising photoactivation by BL. $B$, Quantitative analysis of MF effect on the BL-induced $V_{m}$ changes to cells expressing CRY variants. C, RMP measured before light stimulation. All values shown are means \pm SEM and $n$ is shown in each bar. ${ }^{* *} p<0.01$.

al., 2012). The W342 radical cation is proposed to be a member of the magnetically sensitive radical pair in CRY (Maeda et al., 2012). Expression of $\mathrm{CRY}{ }^{\mathrm{W} 342 \mathrm{~F}}$ in aCC/RP2 failed to produce a detectable change in membrane potential when exposed to BL. However, in the presence of an MF, BL was able to evoke a significant depolarization $(+\mathrm{BL},-\mathrm{MF}=\Delta-0.01 \pm 0.29 \mathrm{mV}, n=10, \mathrm{vs}+\mathrm{BL},+\mathrm{MF}=$ $\Delta 1.45 \pm 0.37 \mathrm{mV}, p=0.006, n=10$; Fig. $4 A, B)$, suggesting that a single mutation to the Trp triad is sufficient to alter the response of CRY to BL, but does not prevent activation in the co-presence of an MF. Previous studies of circadian behavior have similarly shown a marked reduction in the response of $c r y$-null adult flies expressing $\mathrm{CRY}^{\mathrm{W} 342 \mathrm{~F}}$ to $\mathrm{BL}$, whereas, paradoxically, sensitivity to MF exposure is maintained (Gegear et al., 2010; Fedele et al., 2014b). No changes in RMP were observed between the $-\mathrm{MF}$ and $+\mathrm{MF}$ conditions in the absence of light exposure (Fig. 4C).

\section{C-terminal is essential for CRY-dependent sensitivity to} an MF

Because disruption to the Trp triad did not affect CRY sensitivity to an MF, we examined additional regions of the protein. Dele- 
tion of residues $521-540$ from the C-terminal (CRY $\left.{ }^{\Delta 14.6}\right)$ confers a constitutively active status to CRY (Dissel et al., 2004), which can be further activated by BL (Dissel et al., 2004; Fedele et al., 2014b). The effect of MF observed on the circadian period of wild-type flies, however, is not evident in those expressing $\mathrm{CRY}^{\Delta 14.6}$, whereas an effect of MF is retained on locomotor hyperactivity (Fedele et al., 2014b). This suggests that the C terminus is required for some aspects of CRY signaling, but not others. Expression of CRY ${ }^{\Delta 14.6}$ in aCC/RP2 neurons showed a marked depolarization of membrane potential consequent to BL exposure, which is slightly increased compared with expression of wild-type CRY $(+\mathrm{BL},-\mathrm{MF}=\Delta 2.63 \pm 0.35 \mathrm{mV}, n=10)$. Strikingly, the same exposure to BL in the presence of an MF produced no potentiation of the effect on membrane potential $(+\mathrm{BL},+\mathrm{MF}=\Delta 2.29 \pm 0.35 \mathrm{mV}, n=10, p=0.50$; Fig. $4 A, B)$. Expression of CRY ${ }^{\Delta 14.6}$ results in a modest, but not statistically significant, depolarization of basal membrane potential compared with controls $\left(\mathrm{ElaV}^{\mathrm{C} 155}\right)$ in the absence of $\mathrm{BL}$ exposure (Fig. 4C), which is consistent with a constitutively active state. Therefore, residues within the C-terminal of CRY are required for neuronal sensitivity to an MF, which mirrors the requirement of this region for magnetic sensitivity, negative geotaxis (Fedele et al., 2014a), and circadian period (Fedele et al., 2014b).

\section{Discussion}

The precise biophysical origin of animal magnetosensitivity remains unclear. Among the proposed primary magnetoreceptors is the flavoprotein CRY, which is thought to provide geomagnetic information via a quantum effect in a light-initiated radical pair reaction. However, the involvement of this mechanism remains hypothetical until the physical process in a magnetoreceptor is shown to result directly in a physiological response, like an electrical response in a receptor cell (Lohmann, 2010). We showed previously that the Drosophila CNS, when exposed to BL during embryogenesis, develops heightened seizure susceptibility at postembryonic stages. MF exposure coupled with BL illumination significantly potentiates this effect. Experiments performed on cry-null mutants, or when stimulating at wavelengths not overlapping with the absorption spectrum of oxidized CRY (e.g., $590 \mathrm{~nm}$ ), showed no impact of an MF on seizure duration. We postulated that MF exposure resulted in circuit instability due to potentiation of a CRY-mediated disturbance of neuronal activity during the embryonic stage, when the CNS is particularly sensitive to modifications (Giachello and Baines, 2015). Here, we provide direct experimental evidence that the presence of a modest-strength MF is sufficient to potentiate the effect of photoactivated CRY on increasing neuron action potential firing rate. These data provide the elusive physiological response in a receptor cell for CRY-dependent magnetoreception.

CRY photoactivation in the Drosophila brain is known to result in depolarization of the membrane in ILNv's and increased action potential firing (Fogle et al., 2011). Experiments suggest that this involves deactivation of a potassium channel through interaction of photoactivated CRY and the $\beta$-subunit $\left(\mathrm{K}_{\mathrm{v}} \beta\right)$ redox sensor HK (Fogle et al., 2015). In the present study, we show that BL-induced CRY activity also works by a similar, if not identical, mechanism in Drosophila motoneurons. We also show that the presence of an external MF potentiates CRY activity. Electrophysiological recordings clearly show that the presence of a 100 $\mathrm{mT}$ MF potentiates both depolarization of membrane potential of aCC/RP2 neurons and increase in input resistance after CRY photoactivation. Both of these observations are consistent with a reduction in potassium permeability. Further, the resultant in- crease in membrane excitability would be predicted to promote network hyperexcitability consistent with an enhanced seizure phenotype in later larval life (Marley et al., 2014; Giachello and Baines, 2015).

The RPM predicts a nonlinear response with increasing MF strength and that the "phase" of the MF effect (i.e., whether an increase or decrease is induced in a measure) should be opposite for weak and moderate fields. We chose to use a moderate field exposure with permanent magnets to saturate the Zeeman effect on the radical pair, which is likely to illicit a larger response to MF at the molecular level (Woodward, 2002). Use of permanent magnets also removes the confounding variables of vibration and heating, which are possible when using the electromagnets necessary for $\mu \mathrm{T}$ exposure. The field at the sample position has reasonable uniformity $(100 \pm 6 \mathrm{mT})$ and good reproducibility. The similarity between the effects of CRY mutations (CRY ${ }^{\mathrm{W} 342 \mathrm{~F}}$ and $\mathrm{CRY}^{\Delta 14.6}$ ) to published behavioral observations (Fedele et al., 2014a; Fedele et al., 2014b) produced using weak fields is striking. Further, although our effects may be considered agonistic (i.e., potentiating the effect of CRY), exposure of adult flies to weak fields in behavioral assays results in an antagonistic effect compared with BL alone (Fedele et al., 2014a). One might expect, therefore, that the effect of $\mathrm{BL}$ on membrane potential in the presence of weak fields might be diminished compared with BL alone (i.e., antagonistic). Opposite effects of weak and moderate $\mathrm{MF}$ are consistent with, and indeed could be a prediction of, an RPM.

Interestingly, however, opposing effects of MF have also been observed-for example, on the circadian period of Drosophila (Yoshii et al., 2009; Fedele et al., 2014b)—-that appear to result from differing wavelengths of light rather than different magnitudes of MF. Whereas a $300 \mu \mathrm{T}$ MF produced a period shortening under light of 430-470 nm (Fedele et al., 2014b), under light of 445-495 nm (Yoshii et al., 2009) or $500 \pm 20$ nm (Fedele et al., 2014 b), a period lengthening was observed. A similar influence of wavelength could be at play here: the antagonist effect of $\mu \mathrm{T} \mathrm{MF}$ observed on the negative geotaxis of adult flies was conducted under $450 \pm 20 \mathrm{~nm}$ and our agonist effects reported here and on the seizure response (Marley et al., 2014) was $<470 \pm 20 \mathrm{~nm}$. These and other (Phillips and Sayeed, 1993) effects of wavelength have been discussed in the context of the photochemical interconversion of different oxidation states of the FAD bound to CRY and are also considered to be consistent with an underlying RPM (Phillips et al., 2010).

Behavioral studies with migratory birds have also revealed that monochromatic light intensity can have a significant impact on magnetoreception (Wiltschko et al., 2007). Among other wavelengths, increasing the intensity of BL ultimately disrupted orientation along the migratory direction and the effect speculated by the investigators might be due to photoactivation of the birds' color cones above a certain threshold. If this were indeed the reason, it would not be a consideration in the experiments described here, where our measurements are on single motoneurons.

The fact that expression of CRY ${ }^{\mathrm{W} 342 \mathrm{~F}}$ removes the effect of $\mathrm{BL}$ but not of $\mathrm{MF}$ is intriguing. Is it possible that, although the MF effects appear to require light, photoactivation and the influence of MF are in some way separated? It has been proposed that the magnetically sensitive radical pair is generated in the dark during reoxidation of the flavin bound to CRY after photoreduction (Wiltschko et al., 2016). However, such an explanation would still require photoreduction and alternative photo-induced electron transfer pathways have been identified in Trp triad variants in vitro (Biskup et al., 2013) and FAD photoreduction observed in 
similar variants in vivo (Engelhard et al., 2014). Interestingly, these alternative pathways appear to be less efficient than the Trp triad and produce lower concentrations of radicals compared with wild-type CRY. Because the flavin radical is proposed to correspond to the signaling state in Drosophila CRY (Vaidya et al., 2013), this lower radical concentration could in itself explain our observations. It is possible that $\mathrm{CRY}{ }^{\mathrm{W} 342 \mathrm{~F}}$ is still photoactivated, but to a level that induces a change in membrane potential below our detection limit, resulting in no apparent effect of BL. When this photoactivation is potentiated by MF, however, it might increase the concentration of activated CRY ${ }^{\mathrm{W} 342 \mathrm{~F}}$ above a threshold to a point where there is a measurable effect on membrane potential.

In contrast, $\mathrm{CRY}^{\Delta 14.6}$ removes the potentiation by MF of the increase in membrane potential by BL. The deletion of residues 521-540, which confer a constitutively active status to CRY (Dissel et al., 2004), may disrupt a possible interaction with another unknown effector(s) or prevent conformational changes within the protein that are essential for the transduction of signal. The signaling interactions involving CRY here might therefore bear a closer resemblance to those involved in the control of circadian period and negative geotaxis - both of which require an intact C terminus to exhibit magnetosensitivity (Fedele et al., 2014a; Fedele et al., 2014b) - than the interactions that result in locomotor hyperactivity, for which the N-terminal FAD-binding region appears to be sufficient (Fedele et al., 2014b). Alternatively, magnetoreception by CRY may require cyclic changes between an active and inactive state, which this deletion might preclude. This seems less likely in light of the effect of MF on locomotor hyperactivity (Fedele et al., 2014b). Indeed, it is possible that CRY might only be necessary for signaling in animal magnetoreception rather than acting as a magnetoreceptor. We feel that this is unlikely because, if true, it would suggest that Drososphila motoneurons are inherently magnetosensitive, but lack CRY to enable this sensory modality. The precise role of CRY is still uncertain, as demonstrated by the striking observation that the isolated C-terminal region, which lacks the FAD chromophore thought necessary for radical pair photochemistry, is sufficient to facilitate a change in period by an applied MF (Fedele et al., 2014b).

Our results represent an important step in elucidating the link between magnetoreception and neuronal activity to facilitate a better understanding of the mechanisms used by organisms to sense the geomagnetic field. We show for the first time that an MF can affect neuronal activity directly through potentiation of photoactivated CRY. Our data obtained using CRY ${ }^{\mathrm{W} 342 \mathrm{~F}}$ support the existing hypothesis that disruption of the Trp residue at position 342 is not crucial for flies to sense an MF (Gegear et al., 2010; Fedele et al., 2014b). Our data are also consistent with exposure to an MF increasing the sensitivity of CRY ${ }^{\mathrm{W} 342 \mathrm{~F}}$ to BL, possibly by increasing its stability (Fedele et al., 2014b) or by increasing the concentration of flavin radicals. In contrast, the C-terminal would seem to have a prominent role in enabling CRY to facilitate modulation of neuronal activity by MFs. Exploitation of Drosophila genetics offers the exciting prospect to establish whether CRY is indeed a primary magnetoreceptor and to advance our understanding of the molecular basis of that activity and the mechanism of signal transduction.

\section{References}

Ahmad M, Grancher N, Heil M, Black RC, Giovani B, Galland P, Lardemer D (2002) Action spectrum for cryptochrome-dependent hypocotyl growth inhibition in Arabidopsis. Plant Physiol 129:774-785. CrossRef Medline Bae JE, Bang S, Min S, Lee SH, Kwon SH, Lee Y, Lee YH, Chung J, Chae KS
(2016) Positive geotactic behaviors induced by geomagnetic field in Drosophila. Mol Brain 9:55. CrossRef Medline

Baines RA (2004) Synaptic strengthening mediated by bone morphogenetic protein-dependent retrograde signaling in the Drosophila CNS. J Neurosci 24:6904-6911. CrossRef Medline

Baines RA, Bate M (1998) Electrophysiological development of central neurons in the Drosophila embryo. J Neurosci 18:4673-4683. Medline

Baines RA, Robinson SG, Fujioka M, Jaynes JB, Bate M (1999) Postsynaptic expression of tetanus toxin light chain blocks synaptogenesis in Drosophila. Curr Biol 9:1267-1270. CrossRef Medline

Baines RA, Uhler JP, Thompson A, Sweeney ST, Bate M (2001) Altered electrical properties in Drosophila neurons developing without synaptic transmission. J Neurosci 21:1523-1531. Medline

Biskup T, Paulus B, Okafuji A, Hitomi K, Getzoff ED, Weber S, Schleicher E (2013) Variable electron transfer pathways in an amphibian cryptochrome: tryptophan versus tyrosine-based radical pairs. J Biol Chem 288: 9249-9260. CrossRef Medline

Ceriani MF, Darlington TK, Staknis D, Más P, Petti AA, Weitz CJ, Kay SA (1999) Light-dependent sequestration of TIMELESS by CRYPTOCHROME. Science 285:553-556. CrossRef Medline

Dissel S, Codd V, Fedic R, Garner KJ, Costa R, Kyriacou CP, Rosato E (2004) A constitutively active cryptochrome in Drosophila melanogaster. Nat Neurosci 7:834-840. CrossRef Medline

Dodson CA, Hore PJ, Wallace MI (2013) A radical sense of direction: signalling and mechanism in cryptochrome magnetoreception. Trends Biochem Sci 38:435-446. CrossRef Medline

Emery P, Stanewsky R, Helfrich-Förster C, Emery-Le M, Hall JC, Rosbash M (2000) Drosophila CRY is a deep brain circadian photoreceptor. Neuron 26:493-504. CrossRef Medline

Engelhard C, Wang X, Robles D, Moldt J, Essen LO, Batschauer A, Bittl R, Ahmad M (2014) Cellular metabolites enhance the light sensitivity of Arabidopsis cryptochrome through alternate electron transfer pathways. Plant Cell 26:4519-4531. CrossRef Medline

Fedele G, Green EW, Rosato E, Kyriacou CP (2014a) An electromagnetic field disrupts negative geotaxis in Drosophila via a CRY-dependent pathway. Nat Commun 5:4391. CrossRef Medline

Fedele G, Edwards MD, Bhutani S, Hares JM, Murbach M, Green EW, Dissel S, Hastings MH, Rosato E, Kyriacou CP (2014b) Genetic analysis of circadian responses to low frequency electromagnetic fields in Drosophila melanogaster. PLoS Genet 10:e1004804. CrossRef Medline

Fogle KJ, Parson KG, Dahm NA, Holmes TC (2011) CRYPTOCHROME is a blue-light sensor that regulates neuronal firing rate. Science 331:14091413. CrossRef Medline

Fogle KJ, Baik LS, Houl JH, Tran TT, Roberts L, Dahm NA, Cao Y, Zhou M, Holmes TC (2015) CRYPTOCHROME-mediated phototransduction by modulation of the potassium ion channel beta-subunit redox sensor. Proc Natl Acad Sci U S A 112:2245-2250. CrossRef Medline

Gegear RJ, Casselman A, Waddell S, Reppert SM (2008) Cryptochrome mediates light-dependent magnetosensitivity in Drosophila. Nature 454: 1014-1018. CrossRef Medline

Gegear RJ, Foley LE, Casselman A, Reppert SM (2010) Animal cryptochromes mediate magnetoreception by an unconventional photochemical mechanism. Nature 463:804-807. CrossRef Medline

Giachello CN, Baines RA (2015) Inappropriate neural activity during a sensitive period in embryogenesis results in persistent seizure-like behavior. Curr Biol 25:2964-2968. CrossRef Medline

Griffin EA Jr, Staknis D, Weitz CJ (1999) Light-independent role of CRY1 and CRY2 in the mammalian circadian clock. Science 286:768-771. CrossRef Medline

Hogben HJ, Efimova O, Wagner-Rundell N, Timmel CR, Hore PJ (2009) Possible involvement of superoxide and dioxygen with cryptochrome in avian magnetoreception: origin of Zeeman resonances observed by in vivo EPR spectroscopy. Chem Phys Lett 480:118-122. CrossRef

Hore PJ, Mouritsen H (2016) The radical-pair mechanism of magnetoreception. Annu Rev Biophys 45:299-344. CrossRef Medline

Immeln D, Weigel A, Kottke T, Pérez Lustres JL (2012) Primary events in the blue light sensor plant cryptochrome: intraprotein electron and proton transfer revealed by femtosecond spectroscopy. J Am Chem Soc 134: 12536-12546. CrossRef Medline

Johnsen S, Lohmann KJ (2005) The physics and neurobiology of magnetoreception. Nat Rev Neurosci 6:703-712. CrossRef Medline 
Jones AR (2016) Magnetic field effects in proteins. Molecular Physics 114:1691-1702.

Kao YT, Tan C, Song SH, Oztürk N, Li J, Wang L, Sancar A, Zhong D (2008) Ultrafast dynamics and anionic active states of the flavin cofactor in cryptochrome and photolyase. J Am Chem Soc 130:7695-7701. CrossRef Medline

Kattnig DR, Evans EW, Déjean V, Dodson CA, Wallace MI, Mackenzie SR, Timmel CR, Hore PJ (2016) Chemical amplification of magnetic field effects relevant to avian magnetoreception. Nat Chem 8:384-391. CrossRef Medline

Levy C, Zoltowski BD, Jones AR, Vaidya AT, Top D, Widom J, Young MW, Scrutton NS, Crane BR, Leys D (2013) Updated structure of Drosophila cryptochrome. Nature 495:E3-E4. CrossRef Medline

Lohmann KJ (2010) Q\&A: animal behaviour: magnetic-field perception. Nature 464:1140-1142. CrossRef Medline

Maeda K, Robinson AJ, Henbest KB, Hogben HJ, Biskup T, Ahmad M, Schleicher E, Weber S, Timmel CR, Hore PJ (2012) Magnetically sensitive light-induced reactions in cryptochrome are consistent with its proposed role as a magnetoreceptor. Proc Natl Acad Sci U S A 109:4774-4779. CrossRef Medline

Marley R, Giachello CN, Scrutton NS, Baines RA, Jones AR (2014) Cryptochrome-dependent magnetic field effect on seizure response in Drosophila larvae. Sci Rep 4:5799. CrossRef Medline

Mouritsen H, Janssen-Bienhold U, Liedvogel M, Feenders G, Stalleicken J, Dirks P, Weiler R (2004) Cryptochromes and neuronal-activity markers colocalize in the retina of migratory birds during magnetic orientation. Proc Natl Acad Sci U S A 101:14294-14299. CrossRef Medline

Nießner C, Denzau S, Peichl L, Wiltschko W, Wiltschko R (2014) Magnetoreception in birds: I. Immunohistochemical studies concerning the cryptochrome cycle. J Exp Biol 217:4221-4224. CrossRef Medline

Painter MS, Dommer DH, Altizer WW, Muheim R, Phillips JB (2013) Spontaneous magnetic orientation in larval Drosophila shares properties with learned magnetic compass responses in adult flies and mice. J Exp Biol 216:1307-1316. CrossRef Medline

Phillips JB, Sayeed O (1993) Wavelength-dependent effects of light on mag- netic compass orientation in Drosophila melanogaster. J Comp Physiol A 172:303-308. CrossRef Medline

Phillips JB, Jorge PE, Muheim R (2010) Light-dependent magnetic compass orientation in amphibians and insects: candidate receptors and candidate molecular mechanisms. J R Soc Interface 7:S241-S256. CrossRef Medline

Rodgers CT, Hore PJ (2009) Chemical magnetoreception in birds: the radical pair mechanism. Proc Natl Acad Sci U S A 106:353-360. CrossRef Medline

Sheeba V, Gu H, Sharma VK, O’Dowd DK, Holmes TC (2008) Circadianand light-dependent regulation of resting membrane potential and spontaneous action potential firing of Drosophila circadian pacemaker neurons. J Neurophysiol 99:976-988. CrossRef Medline

Solov'yov IA, Schulten K (2009) Magnetoreception through cryptochrome may involve superoxide. Biophys J 96:4804-4813. CrossRef Medline

Vaidya AT, Top D, Manahan CC, Tokuda JM, Zhang S, Pollack L, Young MW, Crane BR (2013) Flavin reduction activates Drosophila cryptochrome. Proc Natl Acad Sci U S A 110:20455-20460. CrossRef Medline

VanVickle-Chavez SJ, Van Gelder RN (2007) Action spectrum of Drosophila cryptochrome. J Biol Chem 282:10561-10566. CrossRef Medline

Wiltschko R, Stapput K, Bischof HJ, Wiltschko W (2007) Light-dependent magnetoreception in birds: increasing intensity of monochromatic light changes the nature of the response. Front Zool 4:5. CrossRef Medline

Wiltschko R, Ahmad M, Nießner C, Gehring D, Wiltschko W (2016) Lightdependent magnetoreception in birds: the crucial step occurs in the dark. J R Soc Interface 13: pii: 20151010. CrossRef Medline

Wiltschko W, Wiltschko R (2005) Magnetic orientation and magnetoreception in birds and other animals. J Comp Physiol A Neuroethol Sens Neural Behav Physiol 191:675-693. CrossRef Medline

Woodward JR (2002) Radical pairs in solution. Progress in Reaction Kinetics and Mechanism 27:165-207. CrossRef

Yoshii T, Ahmad M, Helfrich-Förster C (2009) Cryptochrome mediates light-dependent magnetosensitivity of Drosophila's circadian clock. PLoS Biol 7:e1000086. CrossRef Medline

Zoltowski BD, Vaidya AT, Top D, Widom J, Young MW, Crane BR (2011) Structure of full-length Drosophila cryptochrome. Nature 480:396-399. CrossRef Medline 